\title{
Studia
}

SYNCHRONICZNE I DIACHRONICZNE ASPEKTY BADAŃ POLSZCZYZNY

www.wnus.edu.pl/sj | DOI: 10.18276/sj.2020.19-20 | 299-308

\section{EWA PAJEWSKA}

ORCID: 0000-0002-8612-5300

Uniwersytet Szczeciński, Szczecin

ewa.pajewska@usz.edu.pl

\section{Słownictwo ograniczone czasowo i przestrzennie w powieści Wiesława Myśliwskiego Widnokrąg z perspektywy komunikacyjno-językowej}

\author{
Słowa kluczowe \\ słownictwo, granica, pamięć \\ Keywords \\ vocabulary, boundary, memory
}

\begin{abstract}
Bez stów nic się nie wie o sobie. Słowa przecież rosna dopiero $w$ człowieku razem z nim. Wytapiaja się jak z rudy trosk z jego trosk, udręk, cierpien, tez. Nikt nie otrzymuje ich $w$ darze tylko dlatego, że się urodzit, gdzie, kiedy. Cena stów jest nasz los.
\end{abstract}

Wiesław Myśliwski, Widnokrag

Powyższy cytat wprowadza do artykułu, którego celem jest wykazanie, jak ważną rolę w komunikacji z innymi odgrywa wybór konkretnego - konstytuującego jednostkę - słowa, dającego jej wolność budowania własnej tożsamości. Dokonując takiego wyboru, sięga ona do ,archiwum pamięci”, które zawiera zamkniętą w słowach tradycję, hierarchie wartości, konwencje społeczne i językowe modele życia we wspólnocie.

Nadzieję na zatrzymanie słów w zasobie leksykalnym, a co za tym idzie zachowanie pamięci o artefaktach, uczuciach, emocjach i realiach życia codziennego, daje opowiadanie historii własnego życia. Taki charakter ma powieść Wiesława Myśliwskiego Widnokrąg, w której autor wykorzystuje ograniczone czasowo i przestrzennie słownictwo do zrekonstruowania historycznej już rzeczywistości. Jest to w dużej mierze zapis jego własnej 
pamięci, którą odtwarza w formie przekazu literackiego pod wpływem teraźniejszości. Miejscem, w którym rozgrywa się akcja powieści, są okolice Sandomierza w czasie drugiej wojny światowej i w okresie tużpowojennym. Bohaterem i zarazem narratorem jest Piotr, który snuje wspomnienia o swoim dzieciństwie, młodości oraz wkraczaniu w dorosłość. Z pokładów pamięci narratora wyłaniają się niespodziewanie wydarzenia i przedmioty, wokół których odtwarzane są całe historie. Wykorzystane do ich zrekonstruowania słownictwo wychodzi jednak z użycia i pozostaje w czynnym zasobie słownikowym u coraz mniejszej liczby osób. Jest to zjawisko typowe dla wszystkich zmieniających się wskutek procesów społecznych, gospodarczych i kulturowych wspólnot komunikacyjnych, gdyż nie posługują się w życiu codziennym ich desygnatami ${ }^{1}$. Natomiast użycie takich wyrazów we współczesnych tekstach pisanych - przede wszystkim literackich - poszerza krąg osób rozumiejących ich znaczenie, co pozwala na zachowanie tożsamości kulturowej narodu². Konieczne jest w związku z tym nie tylko posiadanie, ale też nabywanie przez odbiorcę nowych kompetencji kulturowych i komunikacyjnych. Pamiętać przy tym należy, że kompetencje te nie zawsze są wspólne dla wszystkich partnerów aktu komunikacji. Ponadto dla wielu osób starszego pokolenia pochodzących z terenów opisywanych w Widnokręgu przywołanie tego słownictwa wiąże się z emocjami, które są już obce młodzieży. Przez starszych wykorzystywane jest ono głównie w narracji wspomnieniowej. Dla osób młodych jest natomiast źródłem wiedzy zapośredniczonej. Pamięć staje się w związku z tym kategorią wyznaczającą zakres tych kompetencji.

Wojciech Chlebda w każdym akcie pamiętania oraz w każdym akcie mówienia o pamięci (relacjonowania jej zawartości) wyróżnia cztery czynniki konstytutywne: podmiot pamięci (ten, kto pamięta), przedmiot pamięci (to, co jest pamięcią obejmowane), treść pamięci (jej zawartość utkaną z materii psychicznej i zrealizowaną w fizycznej relacji) oraz obserwatora (tego, kto postrzega treść pamięci i o niej innych powiadamia) ${ }^{3}$.

Pojęcie pamięci jest bardzo pojemne semantycznie i często wykorzystywane w różnych dyscyplinach w epoce dominacji teorii ponowoczesnych. W Wielkim słowniku języka polskiego pod red. Piotra Żmigrodzkiego pamięć definiowana jest jako 1.'zdolność umysłu

1 O procesach przechodzenia słownictwa do „archiwum językowego” (termin wprowadzony do literatury przedmiotu przez Kwirynę Handke) powstało już wiele opracowań językoznawczych. Zob. Kwiryna Handke, „"Czasowe cezury» i przebieg życia wyrazu”, Synchroniczne i diachroniczne aspekty badań polszczyzny, red. Mirosława Białoskórska, 4 (1998): 9-27; taż, „Pojęcie i termin «archaizm» na tle zawartości polskich leksykonów", Synchroniczne i diachroniczne aspekty badań polszczyzny, red. Mirosława Białoskórska, 5 (1999): 9-20; Bogdan Walczak, „Uwagi o «odchodzącym słownictwie» (w związku z książką K. Handke, H. Popowskiej-Taborskiej i I. Galsterowej)", Synchroniczne i diachroniczne aspekty badań polszczyzny, red. Mirosława Białoskórska, 5 (1999): 21-34.

2 Bogdan Walczak. „Co to są «dawne słowa»”, Studia Językoznawcze. Synchroniczne i diachroniczne aspekty badań polszczyzny 10 (2011): 321-329.

3 Wojciech Chlebda, „Pamięć ujęzykowiona”, Tradycja dla wspótczesności. Ciagłość i zmiana, 6: Pamięć jako kategoria rzeczywistości kulturowej, red. Jan Adamowski, Marta Wójcicka (2012): 111. 
do utrwalania i odtwarzania informacji', 2. 'obraz czegoś, co minęło, zachowany w czyjejś świadomości’4 .

Poddane analizie słownictwo, mające naturę znakową, jest tworzywem dzieła literackiego i pełni w nim różne funkcje. To sprawia, że jego opis musi uwzględnić także perspektywę komunikologiczną. Tekst zajmuje centralne miejsce w procesie komunikacji, a jego semiotyczna natura pozwala na wprowadzenie w proces semiozy wszystkich uczestników aktu komunikacji z ich kompetencjami językowymi, pozajęzykowymi, intencjami, odczuciami.

Funkcją wychodzących z użycia wyrazów w powieści Wiesława Myśliwskiego Widnokrag jest przywołanie zachowanej w pamięci autora/narratora rzeczywistości i przedstawienie jej czytelnikowi, który może znać znaczenie użytych do opisu słów, może ich nie znać i zignorować ten fakt, może też odnaleźć jego znaczenie w słownikach.

Wyekscerpowane słownictwo występuje w tekście literackim zaliczanym do dyskursu wspomnieniowego. Termin ten po raz pierwszy użyty został przez Maurice’a Halbwachsa ${ }^{5}$, którego prace były inspiracją dla Jana Assmana ${ }^{6}$, proponującego, ważny dla językoznawcy, podział na pamięć komunikatywną i pamięć kulturową. Pamięć komunikatywna charakteryzuje się horyzontem czasowym ograniczonym do 80-100 lat, zakreślonym przez życie trzech, czterech pokoleń oraz obecnością w codziennej komunikacji ustnej. Natomiast pamięć kulturowa powstaje w procesie przetwarzania pamięci poszczególnych członków wspólnoty we wspólną dla nich wszystkich świadomość o tym, co było istotne dla nich w przeszłości i co może mieć znaczenie w budowaniu przyszłości.

Używane w tekście słownictwo ma wprowadzić czytelnika w świat widziany z perspektywy dziecka i wchodzącego w dorosłe życie młodego człowieka. W tym wypadku subdyskurs powieściowy staje się składową dyskursu wspomnieniowego, który obejmuje także inne dyskursy, np. rodzinny, polityczny, społeczny, publiczny, kulturowy, historiograficzny, itp. Odwołanie się do własnej pamięci o przedmiotach, zdarzeniach i emocjach wpływa na organizację oraz kształtowanie pamięci zbiorowej, staje się podstawą przekazu społecznego o danym okresie. Filtrowanie pamięci odbywa się zawsze poprzez doświadczenie i wiedzę z całego życia ${ }^{7}$.

Językoznawcy zajmujący się tekstami literackimi stosunkowo niedawno włączyli się w dyskusję nad funkcjami literatury jako medium pamięci. Astrid Erill ${ }^{8}$ wyróżniła trzy

\footnotetext{
4 Piotr Żmigrodzki, Wielki stownik języka polskiego, dostęp 7.08.2019, https://www.wsjp.pl.

5 Maurice Halbwachs, Społeczne ramy pamięci, tłum. Marcin Król (Warszawa: Wydawnictwo Naukowe PWN, 2008).

6 Jan Asmann, Pamięć kulturowa. Pismo, zapamiętywanie i polityczna tożsamość w cywilizacjach starożytnych, tłum. Anna Kryczyńska-Pham (Warszawa: Wydawnictwo Uniwersytetu Warszawskiego, 2015).

7 Maciej Czerwiński, „Semantyczna analiza dyskursu”, w: Jak analizować dyskurs? Perspektywy dydaktyczne, red. Waldemar Czachur, Agnieszka Kulczyńska, Łukasz Kumięga (Kraków: Universitas, 2016), 41-58.

8 Erill Astrid, „Literatura jako medium pamięci zbiorowej”, w: Pamięć zbiorowa i kulturowa. Wspótczesna perspektywa niemiecka, red. Magdalena Sariusz-Wolska (Kraków: Universitas, 2009), 211-247; taż, Kultura
} 
tego typu funkcje. Pierwszą z nich jest gromadzenie i przechowywanie znaczeń i sensów, drugą - zapewnienie danym treściom cyrkulacji zarówno w czasie jak i przestrzeni, a trzecią - uruchamianie wspomnień za pomocą pewnych „wywoływaczy”, którymi mogą być także konkretne słowa. Wpisują się one w szeroki kontekst kreacji świata przedstawionego i jego odbioru. W Polsce temu zagadnieniu poświęcone są prace Wojciecha Chlebdy ${ }^{9}$, Anny Pajdzińskiej ${ }^{10}$ i Waldemara Czachura ${ }^{11}$. Pamięć jednostek tworzy pamięć zbiorową i jej właśnie dotyczy pierwsza językoznawcza monografia autorstwa Marty Wójcickiej pt. Pamięć zbiorowa a tekst ustny ${ }^{12}$.

Wyekscerpowane $\mathrm{z}$ badanego tekstu słownictwo jest wyborem autora artykułu i nie stanowi kompletnej całości. Przede wszystkim są to wyrazy uporządkowane według kręgów tematycznych, konstytuujących pamięć narratora, a których zrozumienie może sprawić problemy współczesnemu młodemu odbiorcy, także przy założeniu, że mamy do czynienia W większości z czytelnikiem niepochodzącym z opisywanego w powieści regionu Polski. Definicje i kwalifikatory podawane są głównie na podstawie Uniwersalnego słownika języka polskiego pod red. Stanisława Dubisza ${ }^{13}$. Wykorzystano ponadto Stownik gwary sandomierskiej Andrzeja Cebuli ${ }^{14}$, który oznaczono skrótem AC, elektroniczną wersję Wielkiego słownika języka polskiego pod red. Piotra Żmigrodzkiego ${ }^{15}$ oznaczoną skrótem WSJP, elektroniczną wersję Stownika języka polskiego PWN ${ }^{16}$ oznaczoną skrótem ESJP oraz elektroniczną wersję Stownika gwar polskich Jana Karłowicza oznaczoną skrótem SGP17.

Dużą rolę w powieści Widnokrąg odgrywa opis przedmiotów będących na wyposażeniu mieszkania. Cechą charakterystyczną dla czasu będącego przedmiotem narracji jest

pamięci, tłum. Magdalena Saryusz-Wolska (Warszawa: Wydawnictwo Uniwersytetu Warszawskiego, 2018).

9 Chlebda Wojciech, „Szkice do językowego obrazu pamięci. Pamięć jako wartość”, Etnolingwistyka 23 (2011), 83-98.

10 Pajdzińska Anna, „Pamięć jako wartość”, w: Człowiek wobec wyzwań wspótczesności. Upadek wartości czy walka o wartości?, red. Jan Mazur, Agata Małyska, Katarzyna Sobstyl (Lublin: Wydawnictwo UMCS, 2007), 253-261.

11 Waldemar Czachur, „Dlaczego pamięć społeczna może być przedmiotem badań lingwistycznych?”, w: Karly na ramionach olbrzymów? Kultura niemieckiego obszaru językowego w dialogu z tradycja 2, red. Joanna Godlewicz-Adamiec, Piotr Kociumbas, Ewelina Michta (Warszawa: Instytut Germanistyki Uniwersytetu Warszawskiego, 2016), 252-260; Waldemar Czachur, red., Pamięć językiem pisana: Pamięć w ujęciu lingwistycznym. Zagadnienia teoretyczne i metodyczne (Warszawa: Wydawnictwa Uniwersytetu Warszawskiego, 2018).

12 Marta Wójcicka, Pamięć zbiorowa a tekst ustny (Lublin: Wydawnictwo UMCS, 2014).

13 Stanisław Dubisz, red., Uniwersalny słownik języka polskiego (Warszawa: Wydawnictwo Naukowe PWN, 2003). Definicje użyte w artykule bez podania skrótu pochodzą z tego słownika.

14 Andrzej Cebula, Stownik gwary sandomierskiej (Sandomierz: Armoryka, 2018).

15 Piotr Żmigrodzki, red., Wielki słownik języka polskiego, dostęp 7.08. 2019, https://www.wsjp.pl.

16 Stownik języka polskiego PWN, dostęp 7.08. 2019, https://sjp.pwn.pl/.

17 Jan Karłowicz, Stownik gwar polskich, dostęp 7.06.1019, https://www.archive.org/stream/sownikgwarpolsk03kargoog/sownikgwarpolsk03kargoog_djvu.txt . 
bieda. Wielu sprzętów, charakterystycznych dla wnętrza w wiejskich domach czy biednych miejskich mieszkaniach, już nie ma. Jedne z nich są typowe dla tych wnętrz, inne świadczą o aspiracjach do lepszego życia. Dlatego pojawiają się takie wyrazy, jak np. tremo (fr. trudeau) przestarz. 'wysokie lustro w ramie, sięgające, pozwalające na oglądanie odbicia całej postaci, często połączone z konsolą (konsolką) do podłogi lub połączone ze stolikiem konsolowym': Zawsze chciała mieć tremo, takie rozkładane, ze skrzydłami, żeby się można przejrzé́ z boków, z tyłu, włosy jak się ułożyły (34) ${ }^{18}$ czy etażerka (fr. étagerè) książk. 'lekki mebel składający się z kilku otwartych półek na książki, pisma, ozdobne drobiazgi': [...] miały gramofon i cała etażerke ptyt z tangami (32). Sprzętami domowymi i przedmiotami codziennego użytku przywołanymi we wspomnieniach są: balia (d-niem. bajle) przestarz. 'duże, zwykle drewniane, naczynie o prostych, niezbyt wysokich bokach, służące do prania bielizny': Każdy będzie miat $w$ domu beczkę i rurki, a nie to w balii czy kotle do prania (242), ciarupa AC 'gliniane garnki, potłuczona porcelana': Po podłodze to jakby ktoś naumyślnie ciarup, szkieł usiat (218), derka (ukr.) przestarz. 'gruby koc, używany zwykle jako nakrycie na konia': [...] na szerokim siedzeniu, które im dziadek aż z dwóch snopków stomy umościt, nakrywając jeszcze derka (303), dzieża przestarz. 'duże, drewniane naczynie do rozczyniania ciasta na chleb; donica': [...] w domu matka takie koła piekła. Dzieża mąki szła (337), fajerka (niem. Feuerkieke) pot. 'krążek żeliwny lub jedna z kilku obrączek żeliwnych zamykających lub zmniejszających otwór w płycie kuchennej lub piecyku': Coś tam miesza w garnku, coś przestawia na fajerkach (11), kołchoźnik (ros.) pot. 'głośnik podłączony do radiowęzła': Kołchoźnik na ścianie maja (352), kopyść przestarz. 'drewniana łopatka lub łyżka o długim trzonku': Gotowała [...] i kazała ojcu pomieszać kopyścia, aby się nie przypaliła (61), lepka AC 'pasek lepkiej bibułki służący do łapania much': [...] spojrzał na lepkę zawieszona u sufitu (199), miednica 'naczynie w kształcie dużej misy służące do mycia się, prania, zmywania, itp.': [...] dolewa goracej wody do miednicy [...] (11), opatka przestarz. 'owalny koszyk zwykle pleciony z wikliny lub łyka, używany w gospodarstwie wiejskim': [...] taszczy opałkę kartofli z piwnicy (199), pogrzebacz 'zagięty na końcu pręt stalowy służący do poprawiania palącego się w piecu węgla lub drewna': Już łapie pogrzebacz, zrywa fajerki (8), przetak rol. 'duże sito z większymi otworami, służące zwykle do odsiewania, czyszczenia ziarna': [...] przytaknęła babka, podnosząc głowę znad przetaka, $w$ którym przebierała fasolę (62), sagan (ros.) pot. 'duży garnek kuchenny, żelazny lub miedziany, używany głównie na wsi’: [...] dolewa goracej wody do miednicy z sagana (11).

Można też wyróżnić grupę wyrazów, które są nazwami ubiorów lub jego części, np. beretka AC 'nakrycie głowy, beret': siedziat [...] w wypłowiałej beretce na głowie (196), burka (ukr.) histor. 'długie, obszerne nakrycie wierzchnie w formie peleryny z kapturem, uszyte z grubego, ciemnego sukna lub filcu, używane dawniej podczas podróży': Nawet burki nie mieli dla niej (583), ciapki AC 'kapcie': [...] ona ciapków miała petno w sieni (34),

18 Cyfry w nawiasach oznaczają numery stron powieści Widnokrąg, na których znajdują się analizowane zwroty. 
giemza (niem. Gemse) rzem. 'wyprawiona skóra kozia używana do wyrobu luksusowego obuwia i galanterii skórzanej’: Ale tutaj musi być na cholewkę taka sama skóra jak w tym, a to giemza (363), kaszkiet (franc. casquette) pot. 'czapka męska z daszkiem', histor. 'w XIX w. nakrycie głowy ze skóry lub filcu, używane przez żołnierzy’: [...] chodził w złotym kaszkiecie (300), koalicyjka wojs. 'wąski, skórzany pas oficerski, przerzucany ukośnie przez lewe ramię i pierś': pas z koalicyjka (61), podkówka rzem. 'okucie w kształcie półkolistym chroniące obcas przed ścieraniem': Ty partaczu! Podkówki ci najwyżej przybijać (360), rubaszka (ros.) et. 'koszula męska, wykładana na spodnie, przepasana pasem lub sznurem, zapinana na lewym ramieniu, noszona w Rosji’: Poza butami zastawit wiele innych rzeczy i rubaszkę, i spodnie [230], zapaska etn. 'wiejski, samodziałowy fartuch z wełny, marszczony, noszony z przodu na spódnicy, służący też do okrycia się’: [...] myła ręce, zakładała zapaskę (209).

Do wyrazów, które także mogą być niezrozumiałe dla współczesnego czytelnika, można zaliczyć nazwy sprzętów używanych w gospodarstwie wiejskim. Należą do nich: latry AC 'boczne deski albo drabiny u wozu': [...] ze złości chwycił się garściami latrów [314], ożóg przestarz. 'kij, często zakrzywiony, do poprawiania ognia w piecu piekarskim lub do wygarniania żużlu i popiołu z pieca kowalskiego': [...] chwycił ożóg (203), reptuch AC 'torba do karmienia koni': [...] nie zdążyt [...] zawiesić reptucha koniom u łbów (385), skobel 'pręt metalowy wbity dwoma końcami w futrynę drzwi, wieko skrzyni, itp., służący do zamykania czegoś, zwykle na kłódkę’: [...] zamknątem stodołę na skobel (176), zajdy AC 'dwuczęściowe sanie, połączone łańcuchem, służące do przewozu drewna' [...] jak ktoś z pola z zajdami szedt, zatrzymywat go i pstryk (22), zatylnik AC 'deska zamykająca z tyłu wóz': [...] to upchało się jakoś [...] już przy zatylniku, gdzie usiadła i Buba (303), żuraw przestarz. 'prymitywny przyrząd do wyciągania wody ze studni, w kształcie drąga dwuramiennego obciążonego ciężarkiem i umieszczonego na wysokiej podstawie': [...] matka, zobaczywszy na podwórzu żuraw, wykrzyknęła [...] (378).

Zmieniły się także zabudowania i ich funkcje, z tego powodu wychodzą z użycia takie wyrazy, które nazywają części budynków w gospodarstwie, np. sasiek rol. 'część stodoły, gdzie składa się zboże, siano, słomę’: [...] opierając się o ścianę [...] sąsieka (175), wrótnie AC 'wrota, brama': Podsunątem się cichutko pod wrótnie (175).

Ograniczony zasięg użycia mają już nazwy owoców, rosnących w przydomowych sadach, takich jak: cukrówka WSJP pot. 1.'odmiana gruszy, mająca średniej wielkości owoce koloru żółtozielonego, niekiedy zarumienione, z soczystym, bardzo słodkim miąższem', 2. owoc cukrówki - drzewa': urwę sobie parę cukrówek (175) czy sralki AC 'niewielkie żółte śliwki’ (23).

Wiesław Myśliwski wykorzystuje w powieści wiele wyrazów, które tworzą emocjonalnie nacechowaną atmosferę minionej epoki. Do takiej grupy można zaliczyć nazwy osób, np. dzierlatka ksiązk. 'wesoła, szczebiotliwa, trzpiotowata, młoda dziewczyna': [...] zachowywały sie jak dzierlatki (232), smark pot. lekcew. 'o kimś młodym, niedorosłym lub z gniewem o dziecku, zwłaszcza o chłopcu’: Aleś ty smark jeszcze (298), szczyl pot. pospol. 
'z niechęcią lub gniewem o dziecku, zwłaszcza o chłopcu': Cóż to za szczyl (265), znajduch ESJP 'gwarowo: osoba w dzieciństwie znaleziona przez aktualnych opiekunów; znajda': Nic dobrego z tego znajducha nie wyrośnie (267), zdzierus 'zdzierca': To ten zdzierus nie tyle od grobu, co od tej ziemi bierze (352). Wychodzą z użycia nacechowane silną ekspresją wyzwiska, takie jak jucha posp. ‘drań, szelma, gałgan': Przewoźnik, jucha, płynie (374) czy kulfon 'pogardliwie o człowieku niezgrabnym, ciężkim, niezdarnym' (359). Do nacechowanych ekspresywnie wyrazów można zaliczyć także wyraz bett notowany przez WSJP z kwalifikatorem pogard. Pot. 'niejasna, niezrozumiała wypowiedź': [...] mówiliśmy, że bełt ma Kaziuń w głowie ze starości (262).

Wielu wyrazów wychodzących z użycia, wyekscerpowanych z powieści Myśliwskiego, nie można połączyć w większe grupy tematyczne. Przykładem może być w tym wypadku nazwa osoby wykonującej nieistniejący obecnie zawód, np. felczer (niem.) med. 'osoba wykonująca zawód zbliżony do zawodu lekarza, ale uprawniona do wykonywania jedynie prostych zabiegów': A może powinieneś do lekarza pojechać. Albo chociaż idź tu do naszego felczera (37). Nieużywane są także nazwy wyspecjalizowanych sklepów, jak np. tokciowy historycz. 'sklep z towarami łokciowymi: W łokciowym mają mieć w przyszłym tygodniu na wsypy (352) czy bławatny ${ }^{19}$ 'sklep, w którym handluje się tkaninami’ [def. E.P.]: [...] dostać sklepik, bławatny (302). Przestały funkcjonować w realiach życia codziennego nazwy niektórych jednostek miary, jak np. kwaterka przestarz. 'dawna jednostka objętości ciał płynnych i sypkich równa $1 / 4$ litra (1/4 kwarty)’: Kupiłam kwaterkę śmietany (353). Do rzadkich wyrazów można zaliczyć też słownictwo z zakresu obrzędowości religijnej, takie jak egzorta (niem. Exhorte) rel. 'krótkie kazanie okolicznościowe, wygłaszane przeważnie na pogrzebie lub w rocznicę czyjejś śmierci’: Ksiądz [...] wygłosił nad ojcem egzorte (508).

Ograniczony zasięg użycia mają wyrazy pochodzące z języka niemieckiego, które występowały w komunikacji potocznej w okresie wojny, a dotyczące zaopatrzenia w żywność, np. bezugszajn 'talon'20: Podwyżkę nawet dali [...] i dodatkowy bezugszajn na kilo kietbasy, kilo cukru (169), szlacht 'rzeź'21: Stworzenie na szlacht poszło (240). Tych wyrazów nie notują wykorzystane słowniki. Podobną grupę stanowią wyrazy pochodzące z języka rosyjskiego, które oddawały realia kontaktów miejscowej ludności z żołnierzami Armii Czerwonej. Ta grupa wyrazów obejmuje nazwy osób: lejtenant 'porucznik': Przyjadę, to żebyś żyt, lejtnant (272), starszina 'stopień podoficerski w armii radzieckiej’: Ojciec leżat już w łóżku i wytrzeszczył tylko na nas oczy, gdy stanęliśmy w progu, ja na przedzie z tym krowim tbem na ramieniu, starszina Iwan za mna (338), tawariszcz 'towarzysz': Niewiele

\footnotetext{
19 Tego wyrazu nie notuje Uniwersalny stownik języka polskiego pod red. Stanisława Dubisza. W elektronicznej wersji Stownika języka polskiego znajduje się przymiotnik bławatny z następującą definicją 'dawniej: wykonany z kosztownej, jedwabnej tkaniny, przeważnie koloru błękitnego'.

20 Wyraz nienotowany w wykorzystanych słownikach.

21 W Uniwersalnym stowniku języka polskiego pod red. Dubisza występuje szlachtować 'dokonywać uboju bydła' z kwalifikatorem przestarz. Zob. Bogusław Nowowiejski, Zapożyczenia leksykalne z języka niemieckiego (Białystok: Dział Wydawnictw Filii UW w Białymstoku, 1996).
} 
jeszcze wtedy wiedziałem o tawariszczu Stalinie, prócz tego, że wyzwolit nas od Niemców (232).

Realia czasu minionego oddają także czasowniki, np. buić się SGP 1. 'gęsto rosnąć', 2. 'wzrastać bujnie do góry': Tak zawsze podlewałam, to się aż buity (268), obstalować przestarz. 'zlecić wykonanie czegoś, zamówić coś, zwykle u rzemieślnika': Nowe mu obstalujemy (380), uflagać AC 'ubrudzić się': Co ty w butach idziesz? Dopiero ich $w$ tej rosie musiałeś uflagać (376), wyprymić AC 'wystroić': Muszę gdzieś czarnej chusteczki pożyczyć na głowe, bo w kapeluszu gadaliby, że się wyprymiłam (358), wyraszplować AC 'spiłować raszplą, stalowym pilnikiem o grubych nacięciach': Dobrze choć wyraszplowaliście? (365), przysłówki i wyrażenia przyimkowe, np. siajniasto AC 'krzywo, krzywymi nogami': Ona idzie siajniasto, a on jakby pod orkiestre szedt (253), na kapke AC 'trochę, cokolwiek': Musiałem jeszcze ze swojej dołożyć na kapkę (368), przymiotniki, np. cajgowy od cajg SGP 'materia wełniana', 'zrobiony z takiej tkaniny': Dobrze, że choć tego garnituru nie sprzedatam. Panu by się cajgowy nadat, a to czysta wetna (356), siajniasty AC 'krzywy': Z grubsza panu mówię [...] siajniasty, nie siajniasty (320), wybulony AC 'wybrzuszony': [...] na którymś z wybulonych przęset mostu (27).

Użyte w badanym tekście wyrazy oddają stan pamięci pokolenia, którego dzieciństwo przypadło na czas wojny. Pamięć ta ma przede wszystkim charakter językowy, gdyż - jak pisze Waldemar Czachur ${ }^{22}$ - powstaje w procesie nominalizacji i orzekania o konkretnych doświadczeniach, a przekazywana w procesie społecznej interakcji ma charakter komunikatywny i kulturowy. Jednostka dysponuje określoną kompetencją językową, na którą składa się znajomość leksyki pozwalającej na nazwanie elementów świata rzeczywistego. Ta rzeczywistość ewoluuje, zmienia się i znika. Wiele ważnych dla jednostki i grupy zjawisk, zachowań oraz przedmiotów przestaje istnieć. Zostają w pamięci tych, dla których były ważne. Dla następnych pokoleń stają się tylko zbiorem zamkniętym w „,archiwum” kulturowym. Tak jak odchodzą ludzie, tak też odchodzą słowa. Literatura pozwala zachować pamięć o ludziach poprzez słowa, które utrwala w pamięci kolektywnej.

\section{Bibliografia}

\section{Źródło}

Myśliwski, Wiesław. Widnokrag, wyd. II. Kraków: Wydawnictwo Znak, 2018.

Asmann, Jan. Pamięć kulturowa. Pismo, zapamiętywanie i polityczna tożsamość w cywilizacjach starożytnych. tłum. Anna Kryczyńska-Pham. Warszawa: Wydawnictwo Uniwersytetu Warszawskiego, 2015.

Balcerzan, Edward. „Granice literatury, granice historii, granice granic”. Teksty Drugie: teoria literatury, krytyka, interpretacja 6 (2004), 11-20.

22 Czachur, „Dlaczego pamięć”, 255. 
Bronikowska-Balewska, Agnieszka. Nie-skończone historie... Ojcowie i synowie w prozie lat dziewięćdziesiątych XX wieku. Poznań: Wydawnictwo „Poznańskie Studia Polonistyczne”, 2016.

Cebula, Andrzej. Stownik gwary sandomierskiej. Sandomierz: Armoryka, 2018.

Chlebda, Wojciech. „Pamięć ujęzykowiona”. W: Tradycja dla współczesności. Ciagłość i zmiana. T. 6: Pamięć jako kategoria rzeczywistości kulturowej, red. Jan Adamowski, Marta Wójcicka, 109-119. Lublin: Wydawnictwo UMCS, 2012.

Chlebda, Wojciech, „Szkice do językowego obrazu pamięci. Pamięć jako wartość”. Etnolingwistyka 23 (2011): 83-98.

Czachur, Waldemar, „Dlaczego pamięć społeczna może być przedmiotem badań lingwistycznych?”. W: Karty na ramionach olbrzymów? Kultura niemieckiego obszaru językowego $w$ dialogu z tradycja 2, red. Joanna Godlewicz-Adamiec, Piotr Kociumbas, Ewelina Michta, 252-260. Warszawa: Instytut Germanistyki Uniwersytetu Warszawskiego, 2016.

Czachur, Waldemar, red. Pamięć językiem pisana: Pamięć w ujęciu lingwistycznym. Zagadnienia teoretyczne i metodyczne. Warszawa: Wydawnictwa Uniwersytetu Warszawskiego, 2018.

Czerwiński, Maciej. „Semantyczna analiza dyskursu”. W: Jak analizować dyskurs? Perspektywy dydaktyczne, red. Waldemar Czachur, Agnieszka Kulczyńska, Łukasz Kumięga, 41-58. Kraków: Universitas, 2016.

Dubisz, Stanisław, red. Uniwersalny słownik języka polskiego. Warszawa: Wydawnictwo Naukowe PWN, 2003.

Erill, Astrid. Kultura pamięci, tłum. Magdalena Saryusz-Wolska. Warszawa: Wydawnictwo Uniwersytetu Warszawskiego, 2018.

Erill, Astrid. „Literatura jako medium pamięci zbiorowej”. W: Pamięć zbiorowa i kulturowa. Wspótczesna perspektywa niemiecka, red. Magdalena Saryusz-Wolska, 211-247. Kraków: Universitas, 2009.

Halbwachs, Maurice. Społeczne ramy pamięci, tłum. Marcin Król. Warszawa: Wydawnictwo Naukowe PWN, 2008.

Handke, Kwiryna. „«Czasowe cezury» i przebieg życia wyrazu”. Synchroniczne i diachroniczne aspekty badań polszczyzny, red. Mirosława Białoskórska, 4 (1998): 9-27.

Handke, Kwiryna. „Pojęcie i termin «archaizm» na tle zawartości polskich leksykonów”. Synchroniczne i diachroniczne aspekty badań polszczyzny, red. M. Białoskórska, 5 (1999): 9-20.

Kaniowska, Katarzyna. „Antropologia i problem pamięci”. Polska Sztuka Ludowa - Konteksty 3 (2003): 62.

Karłowicz, Jan. Stownik gwar polskich. Dostęp 7.06.1019. https://www.archive.org/stream/sownikgwarpolsk03kargoog/sownikgwarpolsk03kargoog_djvu.txt.

Nowowiejski, Bogusław.Zapożyczenia leksykalnezjęzyka niemieckiego. Białystok: Dział Wydawnictw Filii UW w Białymstoku, 1996.

Pajdzińska, Anna. „Pamięć jako wartość”. W: Człowiek wobec wyzwań wspótczesności. Upadek wartości czy walka o wartości?, red. Jan Mazur, Agata Małyska, Katarzyna Sobstyl, 253-261. Lublin: Wydawnictwo UMCS, 2007.

Skowronek, Krystyna, „«Stare», «nowe» i «najnowsze» konteksty językowo-kulturowe”. Horyzonty Wychowania 15 (2016): 47-65.

Stownik języka polskiego PWN. Dostęp 7.08. 2019. https://sjp.pwn.pl/.

Walczak, Bogdan. „Co to są «dawne słowa»”. Studia Językoznawcze. Synchroniczne i diachroniczne aspekty badań polszczyzny 10 (2011): 321-329.

Walczak, Bogdan. „Uwagi o «odchodzącym słownictwie» (w związku z książką K. Handke, H. PopowskiejTaborskiej i I. Galsterowej)". Synchroniczne i diachroniczne aspekty badań polszczyzny, red. Mirosława Białoskórska, 5 (1999): 21-34.

Wójcicka, Marta. Pamięć zbiorowa a tekst ustny. Lublin: Wydawnictwo UMCS, 2014.

Żmigrodzki Piotr, red. Wielki stownik języka polskiego. Dostęp 7.08.2019. https://www.wsjp.pl. 
Słownictwo ograniczone czasowo i przestrzennie w powieści Wiesława Myśliwskiego Widnokrag z perspektywy komunikacyjno-językowej

Streszczenie

Celem artykułu jest przedstawienie z perspektywy komunikacyjno-językowej wybranego słownictwa z powieści Wiesława Myśliwskiego Widnokrag. Zmieniający się - wskutek dynamicznych procesów społecznych, gospodarczych i kulturowych - sposób porozumiewania się powoduje, że część leksyki wychodzi z użycia i pozostaje w pamięci tylko tych osób, dla których jest ważnym składnikiem tożsamości. Zjawisko to ma charakter uniwersalny. Przyjmujemy, że literatura jest podstawowym medium pamięci wspólnoty kulturowej, a leksyka w niej zawarta przekazuje wybrane obrazy życia, pomagając w ich zapamiętaniu lub poszerzając kompetencje odbiorcy o nowe elementy. Słownictwo kreujące obraz świata w powieści Widnokrag rekonstruuje i reinterpretuje przeszłość zarówno u autora/narratora jak i u czytelnika. Wybrane $\mathrm{z}$ analizowanej powieści słownictwo zatrzymane w pamięci jednostki pokazuje rzeczywistość z perspektywy „małej ojczyzny”, umożliwiając czytelnikowi poznanie realiów toczącego się w niej życia, a co za tym idzie poszerzenie własnej pamięci.

\section{Temporarily and spatially limited vocabulary of the Wiesław Myśliwski’s novel Widnokrag from a communicative-linguistic perspective}

Sum mary

The purpose of this article is to provide a communicative-linguistic perspective on the vocabulary selected from the Wiesław Myśliwski's novel Widnokrag. As a result of the changing ways of communication - caused by the dynamic social, economic, and cultural processes - part of the lexis goes out of use and only remains in the memory of those for whom it constitutes a significant element of identity. This phenomenon is of a universal nature. We assume that literature is a basic medium of memory of a cultural community, and the lexis contained in it transfers selected images of life, helping to memorize them or adding new elements to he reader's competences. The vocabulary that creates the image of the world in Widnokrag reconstructs and reinterprets the past both in the author/narrator and in the reader. The vocabulary selected from the analysed novel, retained in the memory of an individual, shows reality form the perspective of a "small homeland", enabling the reader to know the realities of the life lived there, and thereby to extend his or her own memory.

Cytowanie

Pajewska, Ewa. „Słownictwo ograniczone czasowo i przestrzennie w powieści Wiesława Myśliwskiego Widnokrąg z perspektywy komunikacyjno-językowej”. Studia Językoznawcze. Synchroniczne i diachroniczne aspekty badań polszczyzny 19 (2020): 299-308. DOI: 10.18276/sj.2020.19-20. 